\title{
Enabling patient communication for hospitalised patients during and beyond the COVID-19 pandemic
}

\author{
Smitha Ganeshan (D) , Esther Hsiang, Theodore Peng, Nicholas Thomas, \\ Ilana Garcia-Grossman, Kavon Javaherian, Zoe Lyon, Arpana Vidyarthi
}

Department of Hospital

Medicine, University of California San Francisco, San Francisco, California, USA

\section{Correspondence to}

Dr Smitha Ganeshan, University of California San Francisco,

San Francisco, CA 94143, USA; smitha.ganeshan@gmail.com

Received 21 December 2020 Revised 16 February 2021 Accepted 24 February 2021 Published Online First 10 March 2021
Check for updates

(c) Author(s) (or their employer(s)) 2021. No commercial re-use. See rights and permissions. Published by BMJ.

To cite: Ganeshan S,

Hsiang $\mathrm{E}$, Peng T, et al. BMJ

Innov 2021;7:316-320.

\section{INTRODUCTION}

As COVID-19 spread across the globe, hospitals restricted visitors to protect patients and healthcare providers. ${ }^{1}$ The absence of in-person visitors, who play a central role in patient well-being and clinical decision making by clarifying medical histories and bridging linguistic and cultural divides, left patients vulnerable to social isolation, delirium and fragmented clinical care. ${ }^{2}$ With ongoing COVID-19 infections, health systems continue to grapple with how to support patients and loved ones during visitor restrictions. ${ }^{3}$

Many technology-driven innovations emerged during COVID-19 to conserve personal protective equipment, protect healthcare workers and prevent nosocomial transmission, but, to our knowledge, this was the first programme designed by medical trainees with the specific goal of connecting patients with their loved ones. $^{4-8}$ Here, we describe the design and early impact of an inpatient videoconference telehealth initiative, and we provide a model for health systems interested in designing similar telehealth programmes to connect patients and loved ones. The objective of this initiative was to reconnect patients with their loved ones during COVID-19-related visitor restrictions across diverse hospital settings to improve patient experience and care delivery.

\section{METHODS \\ Setting}

Resident physicians and medical students provide clinical care at three affiliated health systems, including a large tertiary referral centre, a county hospital, and a veterans administration hospital (VA). Sites were chosen because of their central

\section{Summary box}

What are the new findings?

- Inpatient telehealth programmes can augment care delivery by enhancing patient connection to outside support systems.

- Successful implementation and sustainability of telehealth programmes require new workflows to minimise burden on frontline clinicians.

- This case study demonstrates that a video visit consult service can be feasibly implemented across diverse health systems.

How might it impact on healthcare in the future?

- In the future, inpatient telehealth programmes may connect patients to social support mechanisms beyond family members and loved ones, including expert consultants from other institutions or patients' outpatient primary and specialist clinicians.

affiliation with the tertiary academic medical centre in which trainees work. Each health system is independently organised with separated electronic health record (EHR) systems, governance, and funding mechanisms. Implementation across different sites helped test the feasibility of a video-conferencing telehealth initiative across disparate settings.

\section{Team design}

The leadership team consisted of resident physicians in the Internal Medicine Residency Programme. Given the diversity in organisational structures, patient populations and resources at each hospital, residents divided into site-based teams. Medical students, who were largely 
Table 1 Project design

\begin{tabular}{llll} 
& Tertiary hospital & County hospital & VA \\
\hline Team structure & 4 resident physician leads & 4 resident physician leads & 3 resident physician leads \\
& 10 medical student volunteers & 3 medical student leads & 4 medical student leads \\
& 1 Faculty mentor & 27 medical student volunteers & 5 iPads \\
Hardware & 20 iPads & 9 iPads & 9 Amazon fires \\
& 5 Portable speakers & 2 Amazon fires & speakers \\
& & 3 Google tablets & Zoom \\
Software & Zoom & 2 portable speakers & Facetime* \\
Workflow & Medical student consult & Zoom & Medical student consult \\
& Provider driven & & Provider driven \\
Sustaining solution & Integrated into hospital's telehealth resource & Integrated into Care Experience team's & Managed by VA Internal Medicine \\
& centre with trained telehealth navigators & nursing-led workflow & resident physicians \\
Funding & GoFundMe & PoFundMe & GoFundMe \\
& Private family grant & Private family grant & Private donations \\
\hline
\end{tabular}

*FaceTime was occasionally used at the VA when requested by patients and loved ones.

VA, Veterans Administration.

removed from clinical responsibilities during initial stages of the pandemic, joined these teams (table 1). Each site developed its own meetings, roles and operations. Weekly cross-site meetings were held to share best practices and solutions to obstacles. ${ }^{910}$

\section{Fundraising and technology}

Guided by literature from the non-profit setting, the team drew on strong levels of motivations for donation during COVID-19 to design the fundraising process, which included research, solicitation and stewardship. ${ }^{11}$ The team created a map of our donor networks and solicited tablet donations, established a crowdfunding campaign, and ultimately raised US\$10 000 to pay for ancillary hardware (eg, speakers and stands).

The repository of tablets, which included Amazon Fire, Android and Apple tablets, were allocated across sites based on demand and information technology (IT) requirements. At the tertiary hospital, devices were customised and enrolled in a secure wireless network for optimal control of network bandwidth, while devices at the county hospital were permitted to operate on guest networks as private devices. At the VA, lack of wireless connectivity initially impeded widespread tablet use until wireless hotspots were obtained and used throughout the hospital.

Multiple software platforms were trialled in parallel and evaluated based on criteria including privacy, security and familiarity. Zoom was ultimately chosen for video conferencing calls based on its support for multiple callers, short learning curve for participants and providers, and Health Insurance Portability and Accountability Act (HIPAA) compatibility. ${ }^{12}$

\section{Workflows}

To maximise use of a limited number of tablets and minimise the number of individuals to be trained, medical student-led consult teams were created to coordinate video visits. To request a visit, any clinician could page the consult team during the business hours. The consult team coordinated with the patient and loved ones to obtain consent, download and troubleshoot Zoom, schedule visit times and set up the tablet (figure 1). Many patients were elderly with limited English proficiency, experienced challenges with navigating technology, did not own video-enabled devices, or were too ill to reach out to loved ones on their own. In response to challenges, the designed workflows involved hands-on support to organise and set up video conferencing calls for patients. For patients in the intensive care units, students remained nearby to provide ongoing technological support throughout the duration of the video conferencing call.

At the tertiary hospital, in response to requests for after-hour consults, a 'provider-driven' self-checkout workflow was developed for residents and nurses to checkout tablets on demand. Based on initial success, the other two hospitals also established 'providerdriven' systems (figure 1).

\section{Sustainability}

Each site engaged with stakeholders to design sustainable solutions. At the tertiary hospital, the team worked with a newly established institutional inpatient telehealth team to design an inpatient video visit navigator (IVN) role in which a dedicated employee could subsume the responsibilities of volunteer students (table 1). In this model, a clinician places a consult order in the EHR to the remote IVN with information about the requested consult including who should join the meeting, the type of meeting requested (eg, social visit, caregiver teaching), and any additional information about the consult. The IVN role is staffed by a trained health system employee with access to the EHR, which provides access to 


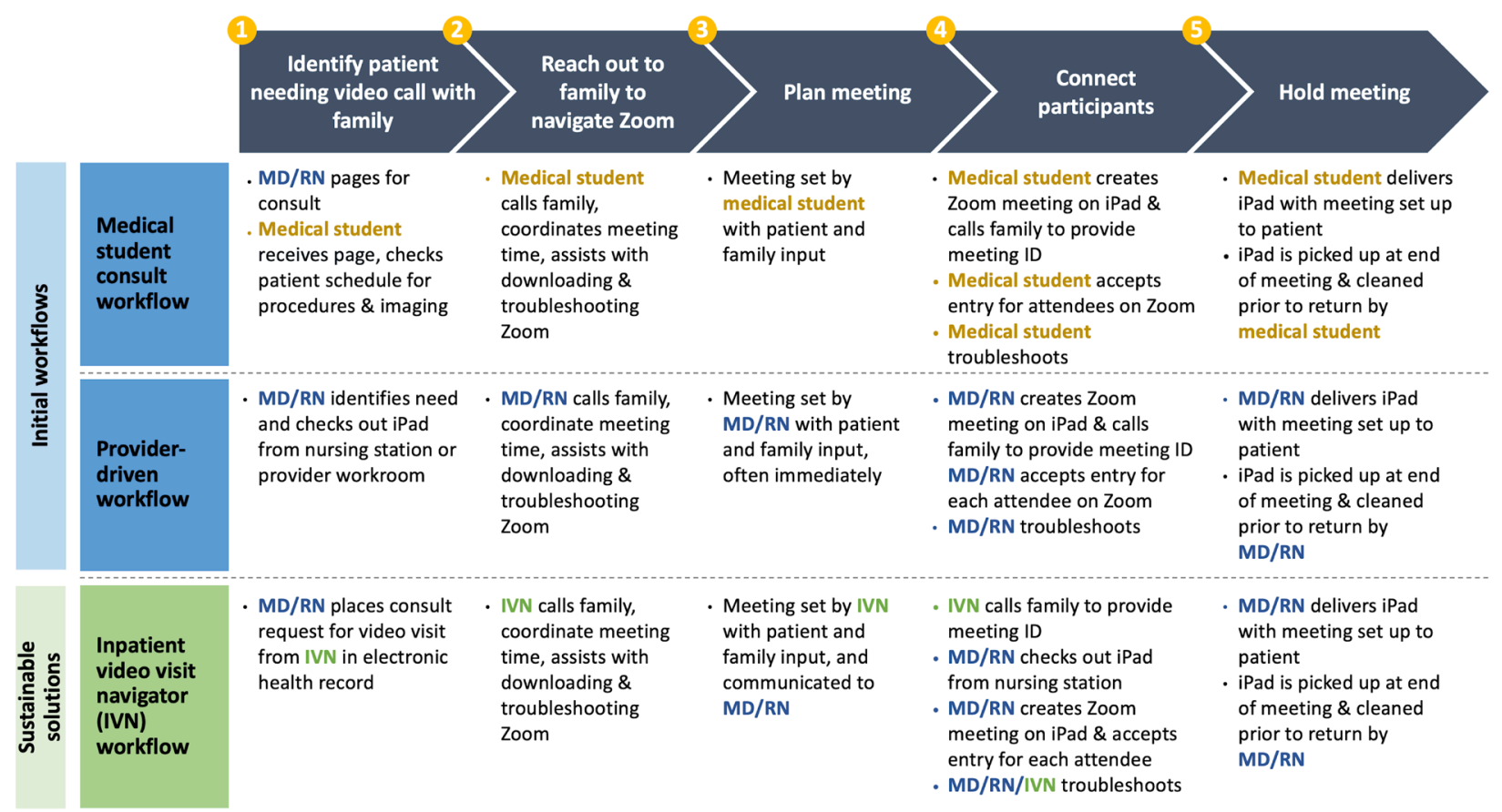

Figure 1 Video visit workflow design. MD, Medical Doctor; RN, Registered Nurse.

information about the patient's medical context. The IVN role is suitable for individuals trained as nurses, medical assistants and licensed vocational nurses. The IVN helps loved ones download and troubleshoot Zoom and sets up the video call on a secure tablet with the help of the patient's bedside nurse. Given the programme's success and ongoing need, the health system provided staffing for two full-time video navigators who coordinate video visits from 8:00-20:00 hours daily. Further, a private family donation provided funding to expand efforts at the tertiary hospital and the county hospital.

\section{RESULTS}

Video visits began on 9 April 2020, 1 month after visitors were prohibited from hospitals in San Francisco per the citywide public health mandate. Over 100 visits were completed by early May and 456 visits by early June, which accounted for 190 unique patients. Approximately 52\% of patients requested repeat calls. Video visits were conducted in 12 different languages with $71.6 \%$ of calls in English, $10.0 \%$ in Spanish, 9.5\% in Cantonese. Most video visit consults came from Medicine and intensive care units (63\%) and neurology/neurosurgery services (22\%). Many of the telehealth use cases were similar across sites; the most common use cases for video visits included connecting patients to family, medical updates and decision making with providers, end-of-life care and caregiver teaching. However, unique site-specific cases also emerged (table 2).

\section{DISCUSSION}

In response to visitor restrictions during COVID-19, medical trainees rapidly developed, designed and implemented a patient-centred, sustainable telehealth programme across three hospitals to connect patients and loved ones and improve clinical care. We describe below several key aspects of the initiative realised through the process of implementation.

\section{Early barriers and solutions}

The need to overcome early barriers led to frequent communication among team leads at each site, sharing learnings and resources. Examples of initial barriers included unmet needs for video calls, low awareness and utilisation of tablets for video calls, lack of knowledge around using new technology platforms such as Zoom, and inefficiencies in setting up calls with families. Ultimately, sites converged on a centralised consult service, which met key considerations including the need to have personnel with deep knowledge of workflows, alleviate frontline staff of additional responsibilities and maximise use of a limited number of tablets. Analysis of this initiative's implementation highlighted key drivers of organisational buy-in, including openness to change during COVID-19 and alignment of initiative goals with the organisation's mission to deliver patient-centred care.

\section{Additional benefits beyond initial expectations}

The use of tablets extended beyond their original purpose. At the tertiary hospital, tablets were used by patients to attend alcoholics anonymous meetings, and 
Table 2 Use cases for video visits between patients and loved ones

\begin{tabular}{|c|c|c|c|}
\hline & Tertiary hospital & County hospital & VA \\
\hline No of patients connected in 6 weeks* & 156 & 255 & 45 \\
\hline Common use cases & \multicolumn{2}{|c|}{$\begin{array}{l}\text { For hospitalised patients to connect directly with families } \\
\text { For medical updates and decision-making } \\
\text { For end-of-life care } \\
\text { For caregiver teaching } \\
\text { For orienting delirious patients }\end{array}$} & $\begin{array}{l}\text { For example, patient with respiratory } \\
\text { failure talked to children prior to } \\
\text { intubation } \\
\text { For example, physician interfaced with } \\
\text { multiple family members, consulting } \\
\text { teams, and patient at bedside to } \\
\text { discuss goals } \\
\text { For example, multiple family members } \\
\text { virtually present during compassionate } \\
\text { extubation } \\
\text { For example, nurse taught family } \\
\text { caregivers how to administer } \\
\text { enoxaparin } \\
\text { For example, elderly patient became } \\
\text { less agitated after seeing husband }\end{array}$ \\
\hline
\end{tabular}

\begin{tabular}{|c|c|c|c|}
\hline Unique use cases & $\begin{array}{l}\text { For connecting patients to } \\
\text { alternative avenues of support } \\
\text { For example, patient with cirrhosis } \\
\text { attended virtual alcoholics } \\
\text { anonymous meetings while } \\
\text { awaiting liver transplant } \\
\text { For physical and occupational } \\
\text { therapists to motivate patients } \\
\text { For example, patient practised } \\
\text { exercises with her husband daily; } \\
\text { therapists were able to gather a } \\
\text { more informed baseline from family }\end{array}$ & $\begin{array}{l}\text { For enabling international calls } \\
\text { for patients' families } \\
\text { For example, family members from } \\
\text { three countries prayed together } \\
\text { with a patient over video call when } \\
\text { she transitioned to comfort care } \\
\text { For language translation } \\
\text { For example, family member } \\
\text { translated for a patient who } \\
\text { spoke a dialect not understood by } \\
\text { hospital interpreters }\end{array}$ & $\begin{array}{l}\text { For engaging patients in affiliated } \\
\text { nursing facility (ie, community } \\
\text { living centre) } \\
\text { For example, using tablets for } \\
\text { combination of educational games, } \\
\text { books and videos for patients } \\
\text { For enabling patients to pay bills } \\
\text { while hospitalised } \\
\text { For example, patients paid bills at home } \\
\text { with the help of medical students and } \\
\text { social workers }\end{array}$ \\
\hline Provider impact quotes & $\begin{array}{l}\text { 'Nurses are distressed with } \\
\text { the visitor restrictions causing } \\
\text { moral injury for patients and } \\
\text { themselves... these video } \\
\text { capabilities have helped ease the } \\
\text { burden'-ICU unit director }\end{array}$ & $\begin{array}{l}\text { 'We had video calls last night } \\
\text { (with a family) before the patient } \\
\text { passed... I've been doing this for } \\
40 \text { years and what's going on with } \\
\text { the visitor restrictions keeps me up } \\
\text { at night.'-ICU nurse }\end{array}$ & $\begin{array}{l}\text { 'An elderly admitted patient would } \\
\text { barely engage with hospital staff. I } \\
\text { set up a video call with his daughter, } \\
\text { and he became more animated and } \\
\text { talkative than I had ever seen him.'- } \\
\text { Resident physician }\end{array}$ \\
\hline
\end{tabular}

${ }^{*}$ Does not include number of video visits completed for patients with provider-driven and nursing-driven workflow.

ICU, intensive care unit; $V A$, veterans administration.

at the VA, tablets were used to help patients pay bills and access educational materials. While the aim was to reconnect patients and their local loved ones unable to visit, we found that family members from around the globe joined video calls. Even beyond the era of visitor restrictions, patients will continue to benefit from interventions that support active engagement of social support systems. Health systems should build or leverage existing inpatient telemedicine infrastructure to engage loved ones using IVN to field consults across the hospital and coordinate with distanced loved ones on a regular basis.

\section{Value of trainees}

The project also highlights how academic institutions could better capitalise on the diverse skillsets of its workforce, including trainees, to inform clinical care delivery improvement. ${ }^{13} 14$ Resident physicians and medical students frequently bring deep experience in diverse fields adjacent to medicine including operational experience, project management, advocacy, quality improvement and entrepreneurship. Working together, trainees combined their expertise with front-line clinical experiences and tacit understanding of the hospital systems to create this initiative.

\section{Limitations}

The initiative's large scale and compressed implementation timeline was labour-intensive and used an untapped workforce made temporarily available by circumstances surrounding the COVID-19 pandemic. This limitation was mitigated by the development of self-checkout workflows and design of designated roles to assist in connecting patients and loved ones. Health systems frequently have volunteers and employees in need of temporary work accommodations who could be trained to serve in the IVN role.

\section{CONCLUSIONS}

Our rapid design and implementation employed the expertise and availability of medical trainees to improve communication among patients, loved ones and clinical teams through telehealth. This case study can serve as a model for health systems looking to create a sustainable inpatient telehealth programme to connect patients and their loved ones across different 
hospital settings. Further research is needed to elucidate the impact of inpatient telehealth on patient satisfaction and health outcomes.

Twitter Nicholas Thomas@nickthomasmed

Acknowledgements We would like to thank Michelle Mourad, MD and Lev Malevanchik, MD for their support and guidance throughout this project as well as the many trainees who contributed their time and effort to make this project a success.

Contributors SG conceived of and presented the idea and wrote the initial manuscript draft with the help of EH, TP and NT. IG-G, KJ and $\mathrm{ZL}$ provided key contributions to the results and discussions sections. AV served as the senior mentor and supervised the findings of this work as well as provided input on each draft of the paper. All authors discussed the results and contributed to the final manuscript.

Funding The authors have not declared a specific grant for this research from any funding agency in the public, commercial or not-for-profit sectors.

Competing interests None declared.

Patient consent for publication Not required.

Provenance and peer review Not commissioned; externally peer reviewed.

This article is made freely available for use in accordance with BMJ's website terms and conditions for the duration of the covid-19 pandemic or until otherwise determined by BMJ. You may use, download and print the article for any lawful, noncommercial purpose (including text and data mining) provided that all copyright notices and trade marks are retained.

ORCID iD

Smitha Ganeshan http://orcid.org/0000-0003-3868-6813

\section{REFERENCES}

1 Wakam GK, Montgomery JR, Biesterveld BE, et al. Not Dying Alone - Modern Compassionate Care in the Covid-19 Pandemic. N Engl J Med 2020;382:e88.

2 Wolff JL, Roter DL. Family presence in routine medical visits: a meta-analytical review. Soc Sci Med 2011;72:823-31.
3 CDC COVID Data Tracker. Centers for disease control, 2020. Available: https://covid.cdc.gov/covid-data-tracker/\#cases_case sper100klast7days [Accessed 17 Nov 2020].

4 Vilendrer S, Patel B, Chadwick W, et al. Rapid deployment of inpatient telemedicine in response to COVID-19 across three health systems. J Am Med Inform Assoc 2020;27:1102-9.

5 Mann DM, Chen J, Chunara R, et al. COVID-19 transforms health care through telemedicine: evidence from the field. J Am Med Inform Assoc 2020;27:1132-5.

6 Meyer BC, Friedman LS, Payne K, et al. Medical Undistancing through telemedicine: a model enabling rapid telemedicine deployment in an academic health center during the COVID-19 pandemic. Telemed J E Health 2020. doi:10.1089/ tmj.2020.0327. [Epub ahead of print: 07 Oct 2020].

7 Smith SW, Tiu J, Caspers CG, et al. Virtual urgent care quality and safety in the time of coronavirus. Jt Comm J Qual Patient Saf 2021;47:86-98.

8 Car J, Koh GC-H, Foong PS, et al. Video consultations in primary and specialist care during the covid-19 pandemic and beyond. BMJ 2020;371:m3945.

9 Valentine M, Edmonson AC. Improving On-the-Fly teamwork in health care. Available: https://hbr.org/2016/11/improvingon-the-fly-teamwork-in-health-care [Accessed 8 Oct 2020].

10 Edmonson AC. The kinds of teams health care needs.. Available: https://hbr.org/2015/12/the-kinds-of-teams-healthcare-needs [Accessed 8 Oct 2020].

11 Bentz ML, Ahmad J, Rohrich RJ. Fundraising and philanthropy in plastic surgery: an essential tool for academic excellence. Plast Reconstr Surg 2011;127:2108-12.

12 Zoom. HIPAA compliance Datasheet, 2003. Available: https:// zoom.us/docs/doc/Zoom-hipaa.pdf [Accessed Nov 2020].

13 Vidyarthi AR, Baron RB. Financial incentives for residents and fellows: a disruptive innovation to drive quality improvement. Acad Med 2011;86:1338.

14 Vidyarthi AR, Green AL, Rosenbluth G, et al. Engaging residents and fellows to improve institution-wide quality: the first six years of a novel financial incentive program. Acad Med 2014;89:460-8. 